\title{
Digital Storytelling as a Tool for Developing Computer Science Soft Skills in Elementary Learners: A Perspective from a STEM based Informal Learning Environment
}

\author{
Temitope Olokunde \\ Southern University and A\&M College \\ Baton Rouge, Louisiana
}

\begin{abstract}
The research explored the influence of digital storytelling as a tool for developing computer science soft skills in elementary learners. Such skills include: problem solving, critical thinking, creativity, team work, memorization, communication and computational thinking. This was conducted in an informal learning environment(ILE) in the form of an after school program among elementary learners. The findings from the study indicate that informal learning and digital storytelling were beneficial to the elementary learners in the exploratory case study. The research questions were answered based on qualitative data from on-site data sources (interviews, observations and field notes). The study engaged elementary school children in STEM-related activities and digital storytelling in an afterschool program. Digital storytelling is viewed as an approach for enhancing children's expression of their STEM learning experiences via the use of digital devices such as I-pads and laptops. Research in this study investigated the following hypothesis: Digital storytelling, when infused in an afterschool program, changes how elementary students think about computer science and STEM education. To assess this hypothesis, research in this study responded to two questions:
\end{abstract}

1. How does digital storytelling develop computer science soft skills among elementary learners?

2. How does informal STEM learning and digital storytelling affect viewpoints created by elementary learners?

\section{General Terms}

Digital storytelling: combines the art of storytelling with various digital multimedia like images, sound and video[1].

\section{STEM: Science, Technology, Engineering and Mathematics.}

Elementary learner: is a child who is at the beginning stage of learning developing motor, mental, physical and emotional skills[2].

\section{Keywords}

Digital storytelling, Elementary learner, Informal learning, Computer Science

\section{INTRODUCTION}

Research in this study reveals elementary learner's interest in computer science through digital storytelling. This study also investigated the role of an informal learning environment, such as after school programs in stimulating elementary learners' interest in computer science. In this research, the words 'children,' and 'elementary learner' were used interchangeably. A growing body of research suggests that developing STEM proficiency starts early in childhood. Children's awareness of their spatial skills, the ability to create and manipulate mental images, as well as their ability to apply these skills in problem-solving situations are easily developed during the early years[3]. The 21 st century STEM workforce shows a growing concern that there are insufficient numbers of skilled technology workers entering careers in STEM fields such as computer science. These calls for increased interest and participation in STEM-related fields and careers have motivated research in this study. Stories are vital in the lives of children as it helps them to understand their world and share it with others; this can also be applied to how they learn STEM subjects[4].

Teaching and learning STEM subjects at the elementary level should be an interesting and memorable experience. Teaching at this level should ingrain basic knowledge of related subjects in the minds of children beneficial to them in their later years. This indoctrination is especially critical for young children who inspire to become STEM professionals. The current digital age has made it more possible to integrate the use of digital devices in educational settings. Therefore, the presence of these digital devices enables digital storytelling as a tool for learning and teaching in and out of the classroom[5]. A great deal of informal learning contexts takes place outside school which includes but are not limited to museums, libraries, nature centers, science exploration centers, summer camps, zoos, aquariums, community-based organizations and after school programs[6]. These informal environments can be used to motivate STEM learning where children are exposed to the inquiry, concepts and ideas of STEM in such learning environments. Their STEM learning experiences and stories can be expressed using digital storytelling[7]. Robin (2008) suggests that digital storytelling centers on the notion of combining the art of storytelling with various digital multimedia like images, sound, and video[8].

The researcher, therefore, sought to interview a computer science Elementary teacher to gain more perspective and insight on computer science soft skills through digital storytelling in informal learning environments. The research in this study further sought to advance previous research findings by investigating digital storytelling as a tool for children to relive their memories and elevate STEM learning experiences. In informal learning settings, individuals gain experiences, which are "contextual, personal, relevant, collaborative, non-linear, and open-ended"[9]. Informal STEM learning is therefore relevant to this research for nurturing children's interest and participation in STEM 
subjects such as computer science. It is vital that children recall and reflect on their STEM learning experiences. This reflection would help them share and communicate their knowledge and lessons learned on STEM activities with others.

\section{LITERATURE REVIEW}

The review of literature for this study focuses on how elementary learners learn, their learning styles and the role of informal learning and digital storytelling in developing computer science soft skills. A Theoretical framework was developed to guide the research study.

\subsection{Theoretical Framework}

The theoretical framework for this study builds on the following theories: Bloom's taxonomy, Emotional intelligence as a learning theory, Theory of constructivism, and Cognitive theory of multimedia learning. The theoretical framework is depicted in the Fig 1 below:

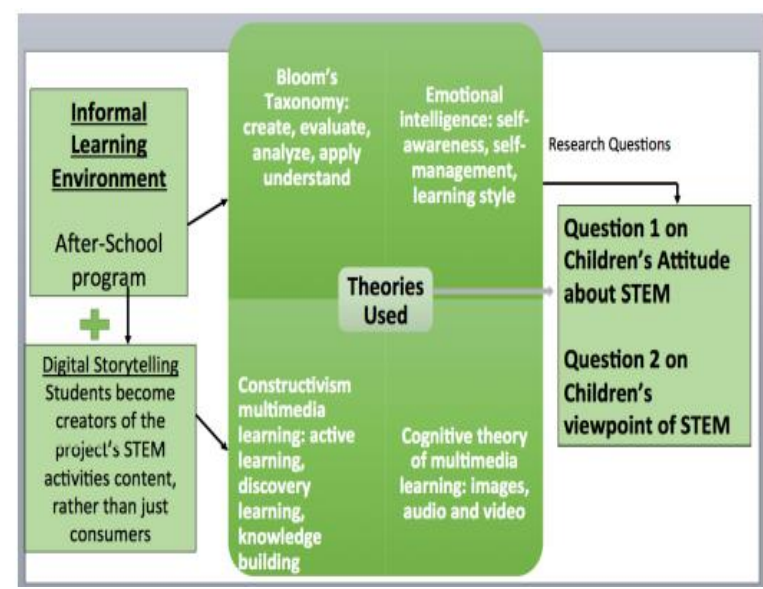

Fig 1:Theoretical framework

Theories used for the theoretical framework are explained below in relation to this research study:

\subsubsection{Bloom's taxonomy}

Bloom's taxonomy classifies learning according to six cognitive levels of knowledge, which are: creating, evaluating, analyzing, understanding and remembering[10]. Applying Bloom's Taxonomy, the researcher examined the impact of digital storytelling on the children's ability to retain information, understand computer science concepts, apply to practical situations, analyze and evaluate their STEM activities, thereby creating something new in the form of their digital stories.

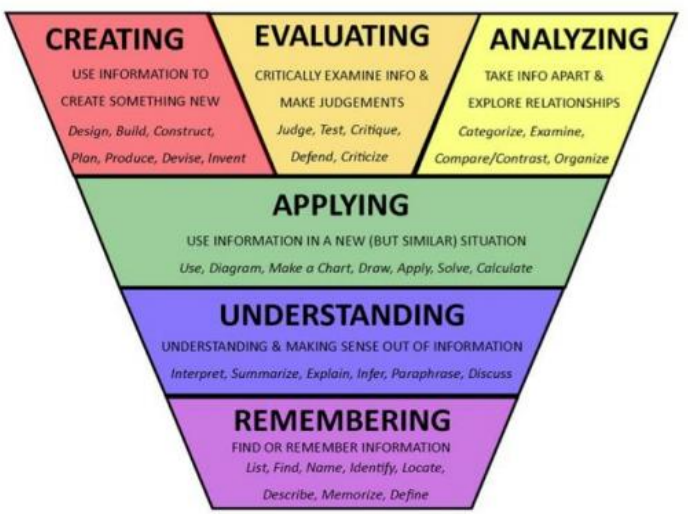

Fig 2: Bloom's taxonomy
The use of digital storytelling in the context of the Bloom's taxonomy fosters the elementary learner's understanding and making sense out of information; this is because of the use of graphics, text and audio in expressing their learning experiences and memories which are typical in computer science activities. This links to their ability to memorize and remember terminologies and concepts, which reflects a cognitive capability.

\subsubsection{Emotional intelligence learning theory}

Emotional intelligence as a learning theory: Emotional intelligence is an important consideration in many aspects, education, personal, life and social. Learning styles entail how individuals begin concentrating on and then processing, internalizing, and finally, retaining new and difficult information that they are taught. Integral to this is the realization that students learn in many different ways[11].

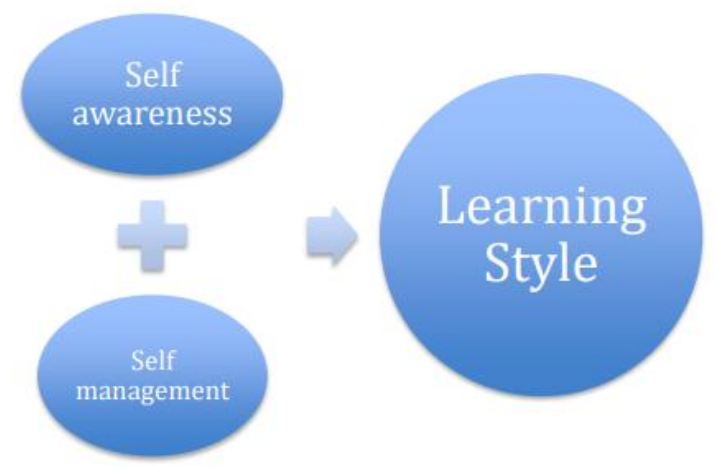

Fig 3: Emotional intelliegence's link to learning style

\subsubsection{Constructivism learning theory}

The theory of constructivism was founded by Jean Piaget and Jerome Bruner emphasizing the importance of the active involvement of learners in constructing knowledge for themselves. As shown in Fig 4, Constructivism comprises active learning, discovery learning and knowledge building, which all promote a student's free exploration within a given framework or structure. Constructivism as a learning theory suggests that people construct knowledge and meaning from their experiences.

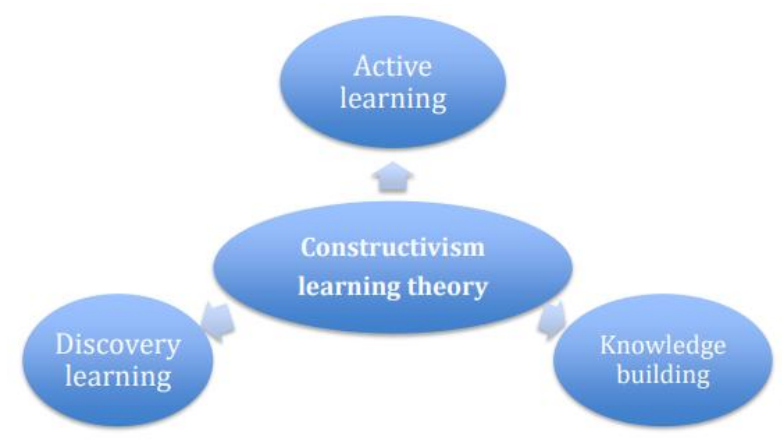

Fig 4: Constructivism learning theory

Active learning is a method of constructivism learning in which students are actively or experientially involved in the learning process[12]. Discovery learning is a method of constructivism learning that takes place in problem solving situations where students interact with their environment by exploring and performing experiments[13]. Knowledge building can be considered as deep constructivism that involves making a collective inquiry into a specific topic 
through group discussions and synthesis of ideas that results in a deeper understanding of the topic. Constructivism helps in developing skills through teaching methods as group based and cooperative work, problem-based activities and discovery learning which are common features in an informal learning environment[14]. The teacher acts as a facilitator who encourages students to discover learning for themselves and to construct knowledge by experimenting and solving real-world problems.

\subsubsection{Cognitive theory of multimedia learning}

Multimedia learning is a cognitive theory of learning, which has been popularized by the work of Richard E. Mayer and other cognitive researchers. The visual representation of the cognitive theory is represented in Fig 5.

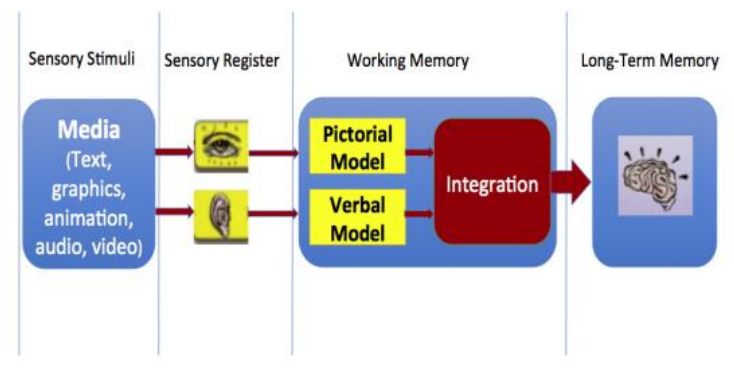

Fig 5: Cognitive theory of multimedia learning

The cognitive theory of multimedia learning strongly applies to the use of digital storytelling in this research study; meaningful learning occurs when an elementary learner is able to construct and create meaning from their STEM learning experiences through a story. Digital storytelling helps the elementary learner to organize their STEM learning information by using multimedia such as: text, graphics, animation and video. These forms of multimedia stimulate the elementary learner's senses to engage in learning. The digital story created from the elementary learner's STEM learning in the informal learning environment integrates into their working memory in the form of images and words; this applies to the dual coding theory that emphasizes the processing of verbal and non-verbal information. The elementary learner develops their cognitive skills in constructing knowledge leading to the possibility of a longterm memory of their STEM knowledge.

\subsection{The Elementary Learners}

The early years are the most important for children because they are the formative years, so it is vital for current and relevant skills to be imparted at an early age in intellectual development. Elementary educators and neurologists express that the first ten years in a child's life are a critical time for brain development[15]. Early years are also viewed as a prime time for cognitive and emotional development. Elementary education has a decisive effect and importance on the evolution and the preparation for the life of a person. Elementary education starts at the age of five until age 12 (grades $\mathrm{K}$ to 6)[16]. The National Association for the Education of Young Children (NAEYC) perceives early years as learning years stating that engaging children in STEM inquiry can provide helpful starting points for developing reasoning[17]. Therefore, good early learning is STEM learning. Children spend a more significant part of their lives learning outside the classroom environment from direct experiences, secondary sources, peers, family, and other adults. The National Research Council on Early Childhood carried out a review stating that children enjoy their early informal experiences. In early childhood, children engage in acquiring fundamental concepts and learning fundamental process skills.

\subsection{Informal Learning Environment (ILE)}

The National Science Foundation defines Informal learning in a broader perspective as learning that happens throughout people's lives in a highly personalized manner based on their particular needs, interests, and past experiences which provides an experiential base and motivation for further activity and subsequent learning[18]. A great deal of informal learning contexts takes place outside school which includes but are not limited to museums, libraries, nature centers, science exploration centers, zoos, aquariums, communitybased organizations, and after-school programs. Martin (2004) recognizes that researchers have long recognized the importance of informal learning environments and opines that informal education will be instrumental in the reform of STEM Education[19]. Informal learning is not guided by a curriculum; it is often thought of as experiential and spontaneous. Informal learning environments (ILE's) give children wonderful opportunities to learn and explore. ILE's offer learners direct access to compelling phenomena in the natural and designed world, and powerful representations of those phenomena. Learning occurs when the meaning people make of their experiences result in change, which may be cognitive, affective, psychomotor and social[7]. Opportunities for children to participate in informal STEM activities are becoming more common. Examples of such opportunities include field trips, after-school programs, and summer camps. Out-of-school contexts for learning, referred mostly as informal science education, include the attendance of museums, science centers, zoos, aquaria, botanical gardens, afterschool programs, and science camps[20]. These informal learning environments offer opportunities for learners to engage in ways that are relevant, rewarding, and enjoyable.

\subsubsection{After-school programs as a STEM based ILE}

After-school program activities are generally considered activities that generate solutions to daily life problems presented in a simple context in which participants construct their understanding[21]. After school programs are well positioned to broaden participation in STEM learning by providing inquiry-based STEM experiences. Afterschool programs can operate before and after school, during school vacations, holidays, and during the summer, in order to meet the needs of working parents. After-school program activities are generally considered activities that generate solutions to daily life problems presented in a simple context in which participants construct their own understanding[22]. After school programs are well positioned to broaden participation in STEM learning by providing inquiry-based STEM experiences. In this research, the afterschool program is viewed as 'STEM clubs after the school hours' and are taken a certain number of times in the school week. After School programs have long aimed to positively influence students' personal development and support their social and emotional growth. After School programs present an excellent opportunity to engage a diverse group of children in the STEM fields. Studies of high-quality afterschool programs have discovered that participating children see a significant improvement in their self-perception, increased positive social behavior. 


\subsection{Digital storytelling as a tool for elementary learners' computer science skills}

A plethora of scholars have defined Digital Storytelling. These definitions focus on combining the art of storytelling with several multimedia such as text, image, audio, music, and video for certain purposes. Robin (2008) suggests that digital storytelling centers on the notion of combining the art of storytelling with various digital multimedia like images, sound, and video. Robin goes on to list the three major elements of digital storytelling which are: purpose, content, quality multimedia resources and grammar usage. Digital storytelling is defined as a group of photos integrated with voice recordings with an exportable factor that extends its reach worldwide[23]. Digital stories combine images such as photos, drawings or other visual art, narration and music to tell a personal or informational narrative[1].

In a National Association for the Education of Young Children survey, educators give examples of how technology supports early learning[17]. These examples include: A 4-year old boy, who speaks only Chinese, uses an iPad to write a digital story that allows him to share details about his home life with other children in his preschool classroom, and A 5year-old child fascinated with transmedia materials that allow him to explore his interests, and develop his small motor and social skills. Digital storytelling is an alternative to paperbased reflection which is a form of digital media primarily focused on the authors' voice[23]. A writer expressed that her five-year old playfully sketched the design cover of her textbook. This five-year old's sketch became the cover for her book[24]. These examples give reason to think that digital storytelling boosts early-learners' interest in learning.

Digital storytelling involves using computers to marry text with art-often still photographs, drawings, paintings, videos as well as narration and music. Such types of storytelling can teach writing and reading skills, motivate learners and help prepare early learners for the "digital sea." Digital storytelling has gained even more popularity through the use of webbased tools and blogs among almost every age group in numerous countries around the world[8]. Research studies have indicated the benefits of digital storytelling when children compose their own stories about a given topic or subject matter. Liu (2011), particularly emphasized how preparing digital storytelling enhances students' creativity[25]. Sanosti (2008) used digital stories to increase social skills for children with disabilities and discovered that the children got better in communication skills[26]. Royer \& Richards (2007) increased students' reading comprehension with digital storytelling, this engaged the students to keep an interest in studying and learning[27]. Digital storytelling increases engagement in a subject matter, story-sharing, collaboration and encourages active participation as well as shared learning and creativity. Elementary learners can, therefore, capture their informal STEM learning experiences through digital storytelling[28].

\section{METHODOLOGY}

This participatory action research study was based upon qualitative data. The research method used was an approach to inquiry involving collecting qualitative data. Therefore, this research study used qualitative research techniques, methods, approaches, concepts for carrying out this research study[29]. Qualitative method is an approach for exploring and understanding the meaning individuals or groups ascribe to a social or human problem[30]. The qualitative methods used in this research study included: observation, interview and field note. Although all elementary learners in the after-school program participated and were observed, 10 were selected for a thorough qualitative analysis.The research design considered for this research study was a case study. A case study is a design of inquiry in which the researcher develops an in-depth analysis of a case, often a program, event, activity, process, or one or more individuals[30]. In this research study, the case study was an afterschool program.

An in-depth analysis of the afterschool program was conducted using multiple sources of information such as: observation, interview and field notes. A case study is beneficial because it investigates a contemporary phenomenon within its real-life context[30]. The investigation in this research study was the role of informal learning and digital storytelling in the real-life context of fostering children's interest in computer science. The research participants for this project were elementary school students between the ages of 5 and 12 in a Southeastern Louisiana elementary school. The afterschool program consisted of 60 elementary learners in kindergarten through 5th grade. All elementary learners in the afterschool program attend the same elementary school where the afterschool program took place. This research was a 6month study, starting in the Fall of 2017 and ending in the Spring of 2018. The case study research design therefore helped to understand the children's views and opinions regarding the activities and their learning trajectories.

\section{DATA ANALYSIS \& FINDINGS}

The findings from this study suggest that digital storytelling is a powerful tool to integrate storytelling with STEM informal learning activities to create more engaging and exciting learning environments. Therefore, this approach has the potential to enhance elementary learners' computer science skills, interest and engagement in STEM education, which provides better educational outcomes for learning. The research sought to establish themes from an interview with an experienced computer science elementary teacher in the study. One of the STEM activities was building a robot. The elementary learners were able to evaluate and analyze the pieces that are put together in creating a Robot.

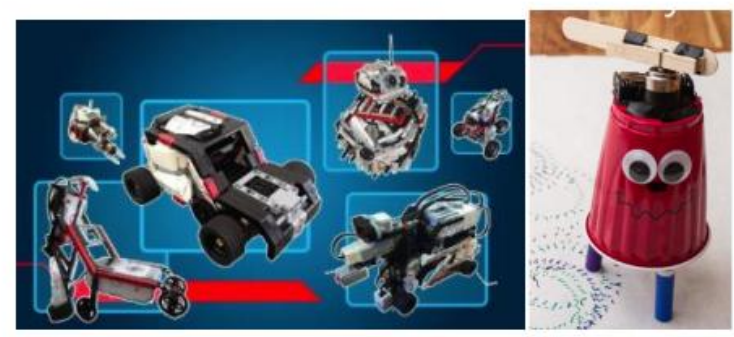

Fig 6: EV3 Mindstorm Robot and Wigglebot

Digital storytelling was a functional tool in helping the elementary learners understand how Robots function, due to the use of media in telling their learning stories. Digital storytelling cuts across auditory, visual and read/write learning styles. The elementary learners were engaged in the use of i-pads in telling their STEM learning stories. Their selfawareness and management led to their discovery of their storytelling preference; some preferred to use graphics and drawings to illustrate their understanding of STEM concepts; some preferred to record their voices to explain their ideas; some preferred to write out what they understood using terminologies they had memorized. Another STEM activity that was in the after school program was 'Plan your Dream 
Vacation': The elementary learners worked in groups as they planned on a budget of $\$ 500$ using a budget sheet; they plan for their flight, car rental, hotel, activities, and food while they are on vacation. They learned basic arithmetic in mathematics such as: addition, subtraction, multiplication and division. The vacation planning is shown in Figure 8 below.

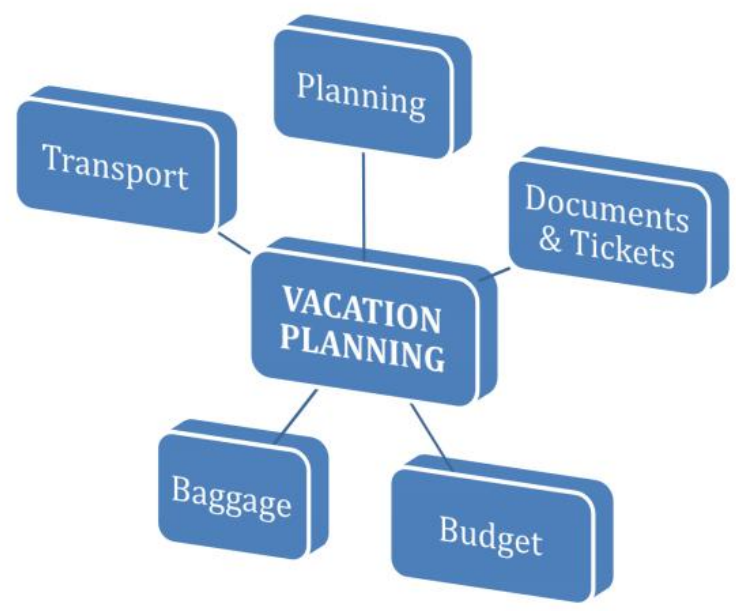

Fig 7: Vacation Planning

This research study revealed that digital storytelling was a vital tool in emphasizing the cognitive theory of multimedia learning. The elementary learners were able to make connections between corresponding representations in the form of images and sounds. As the elementary learners use digital devices in telling their learning story, their working memory was activated to capture pictorial and verbal models of their learning experiences. The sensory register of the elementary learners consisting of their eyes and ears absorbs, process, interpret and retain information, as they create their STEM learning stories. Some snapshots of an elementary learner's digital story is depicted in the Fig 8 and 9:

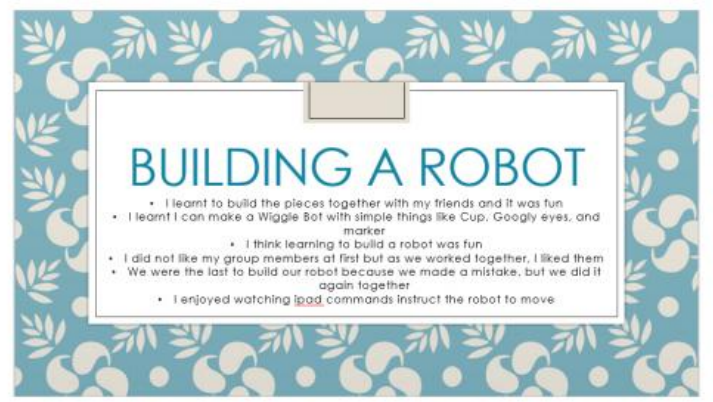

Fig 8: Building a Robot

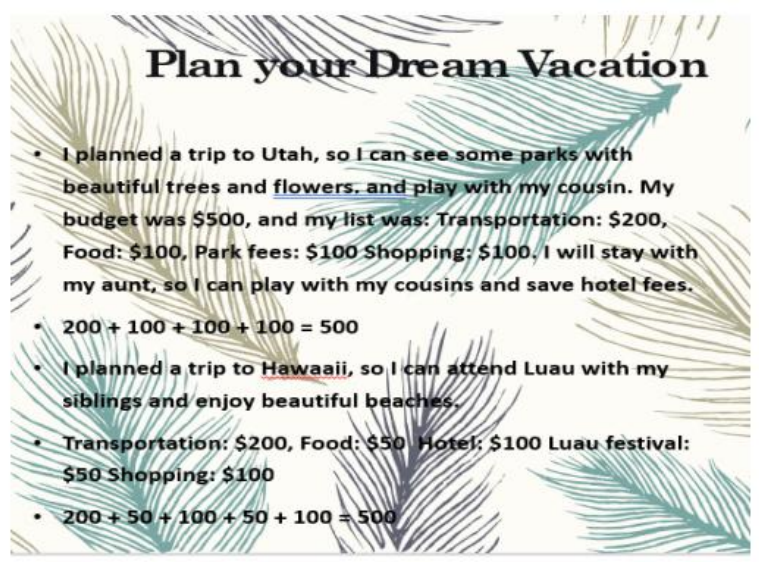

Fig 9: Vacation Budget

The retained information is believed to be stored in their longterm memory for future reference. This research study revealed that the majority of the elementary learners had a positive behavior/attitude towards learning computer science and STEM related activities. This was as a result of an informal learning environment in the form of an afterschool program and digital storytelling as a stimulus for STEM learning. Research Question 1: How does digital storytelling develop computer science soft skills among elementary learners? Response: A Qualitative research method was used to respond to Research Question 1 in the form of observations and field notes.

\subsection{Observations}

Observation was taken using assessments (pre and post assessment). Assessment in this research study helped to provide findings on the elementary learners' attitude towards STEM learning before and after the informal learning environment and digital storytelling. Assessment is the process of gathering and evaluating information on what learners know, understand, and can do in order to make an informed decision about next steps in the educational process[29]. Formative assessment is a range of formal and informal assessment procedures conducted by teachers during the learning process[29]. This research study adapted an informal style of formative assessment, representing the observation technique for responding to Research Question1. The informal assessment in this research study was an ongoing, regular assessment to help the researcher identify learners' strengths and weaknesses, in order to foster learning. Fig 10 below depicts the style of the informal assessment.

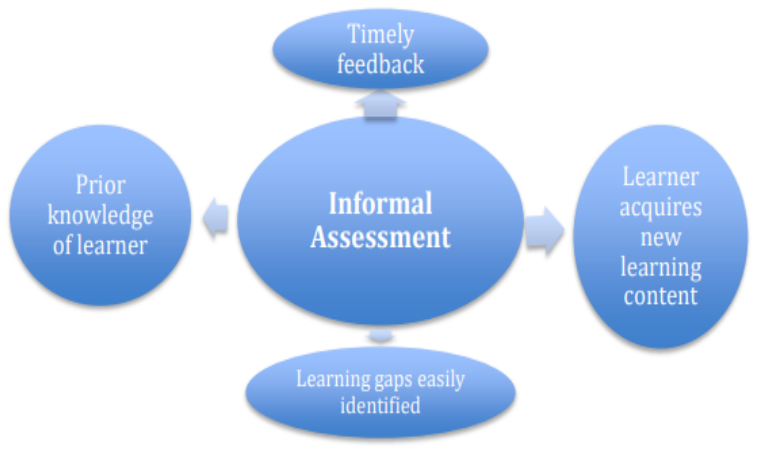

Fig 10: Informal assessment

\subsubsection{Pre-Assessment}

The pre-assessment for this research study was based on interaction and observation with the elementary learners 
group as a whole. Considering this was an informal assessment, the discretion of the researcher was adapted in rating the group from the interactions. Due to the age category (5-12) of the elementary learners, the pretest was taken through informal interaction, child activity and observation; this helped to capture the overall learning atmosphere before and after the research study. The pre-assessment result is illustrated in Fig 11. The assessment was based on a rating scale of the following: Excellent, Good and Fair. The criterion for selecting a rating scale was based on the elementary learners level of self-motivation, interaction, curiosity and exposure.

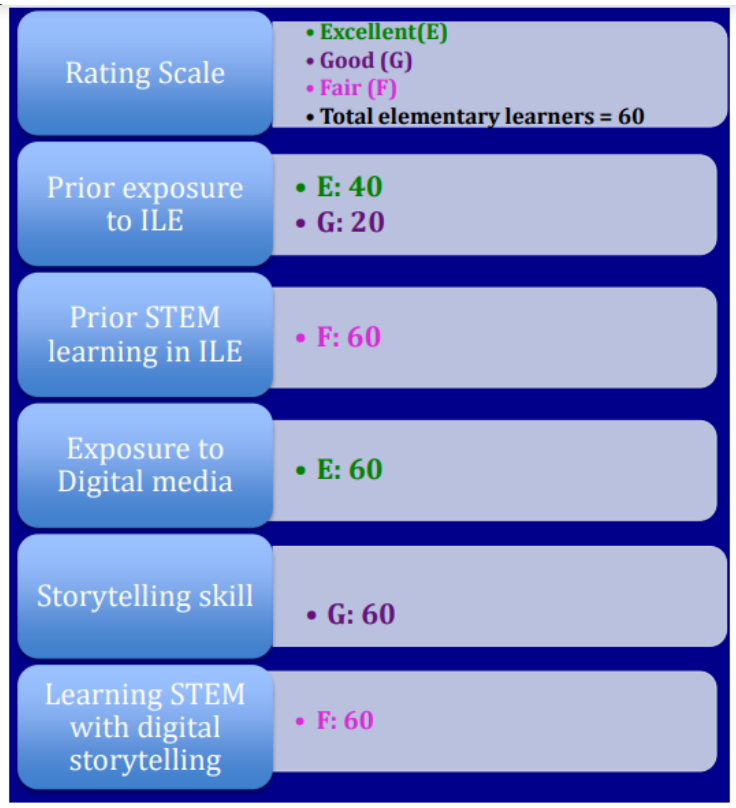

Fig 11: Pre-assessment of research study

\subsubsection{Post-Assessment}

The post-assessment in Fig 12 illustrates the aftermath of elementary learners learning STEM related subjects in an informal learning environment and incorporating digital storytelling into the learning process. Again, just like the preassessment, the post assessment was assessed based on the discretion of the researcher; The post-assessment revealed that the use of informal learning environments and digital storytelling can play a vital role in how elementary learners perceive STEM related subjects.

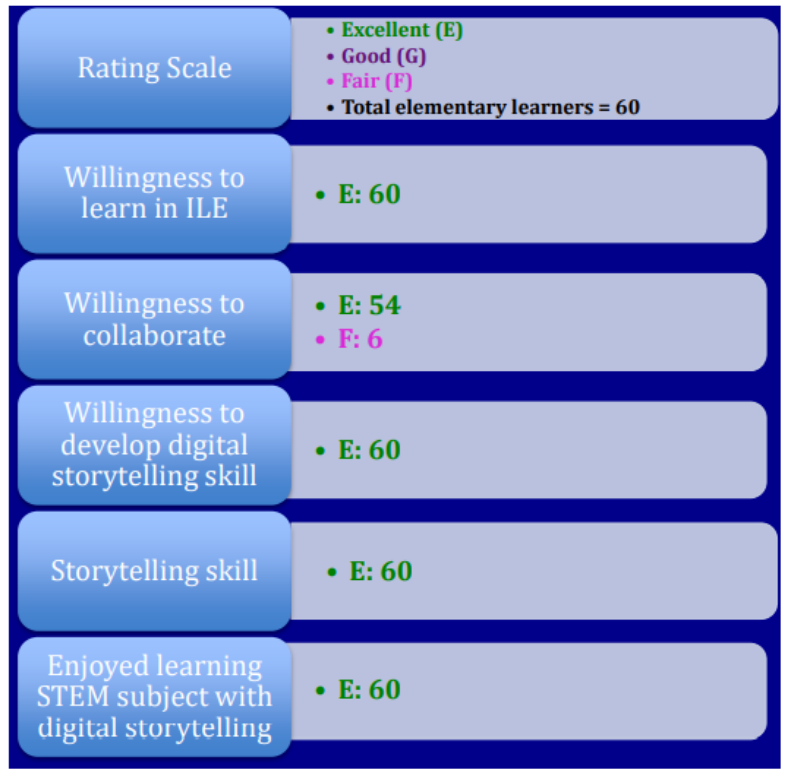

Fig 12: Post assessment of research study

Research Question 2: How does informal STEM learning and digital storytelling affect viewpoints created by elementary learners? Response: A Qualitative research method was used to respond in the form of interview and field notes.

\subsection{Interview}

A computer science teacher in the afterschool program was interviewed as depicted in Fig 13 below.

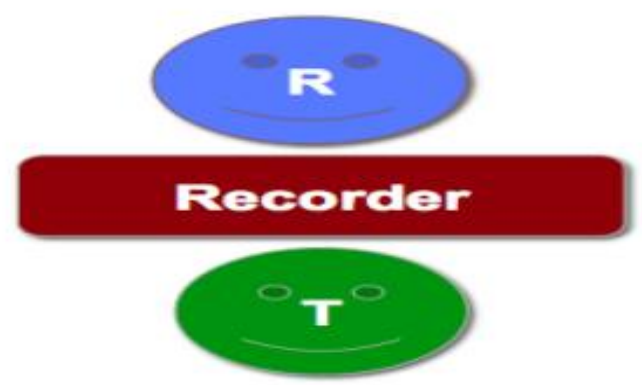

Fig 13: Illustration of Interview Process

The interview led to the following themes:

Theme 1: Children are naturally curious. They are always trying to figure out what works by making things, children are naturally curious and children have questions about their world. Digital storytelling in the learning process builds problem solving, critical thinking and computational thinking which are basic computer science skills.

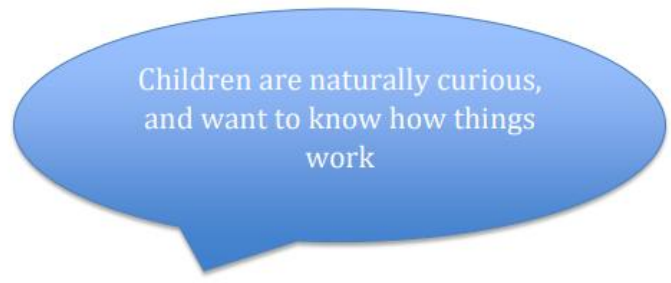

Fig 14: Quote 1 
Theme 2: Level of Children's Interest in STEM Subjects. Children love science and math and are interested based on their curiosity. Some children have reading issues making learning science difficult and challenging. Children enjoy hands-on activity, children love to build and create things. Sometimes children's social awareness to keep up with others distract them from learning STEM subjects.

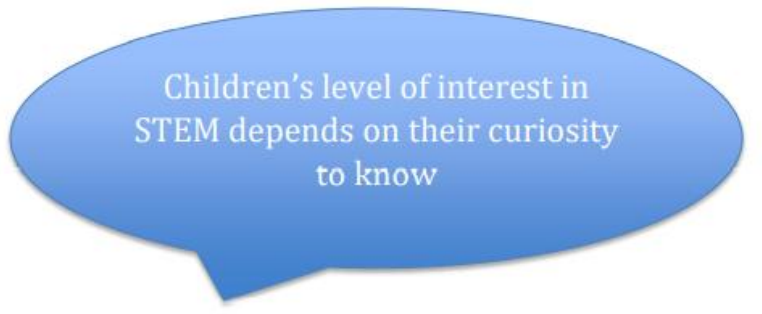

Fig 15: Quote 2

Theme 3: Effective STEM Learning Environment. Having an activity-based STEM Class with trained teachers is a good learning environment. It is important to put children in the learning situation and front load them with content knowledge to think analytically and critically. Connecting in and out-ofschool STEM learning, through strategies like linked curricula, common language and STEM subject matter can enhance an effective STEM learning environment for elementary learners to experience STEM learning.

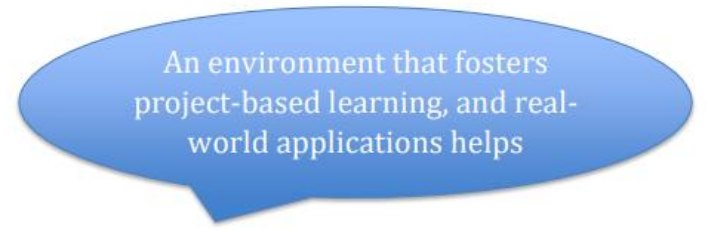

Fig 16: Quote 3

Theme 4: Children's Natural Interest in computer science and other STEM subjects Children's active and natural participation in STEM subjects leads to good use of STEM vocabulary. Children should be presented opportunities to learn STEM concepts in different settings and through different lenses. Their learning can be strengthened naturally when they learn the same skills, ideas, and concepts in different contexts

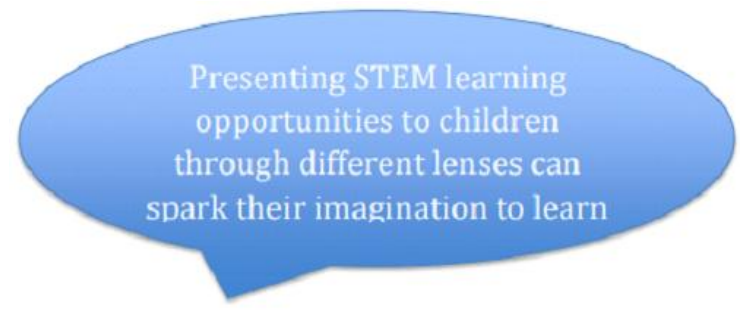

Fig 17: Quote 4

Theme 5: Influence of Digital Devices in Children's computer science skills. We should encourage more critical thinking. Digital devices are great and foster critical thinking which should be established first; the teacher's quote depicted in Fig 18 illustrates this. Digital devices are great for presenting results, but critical and analytical thinking should be considered first. Presenting STEM learning opportunities to children through different lenses can spark their imagination to learn before using digital devices. Children can use digital devices to explore new worlds, make believe, and actively engage in fun and challenging activities.

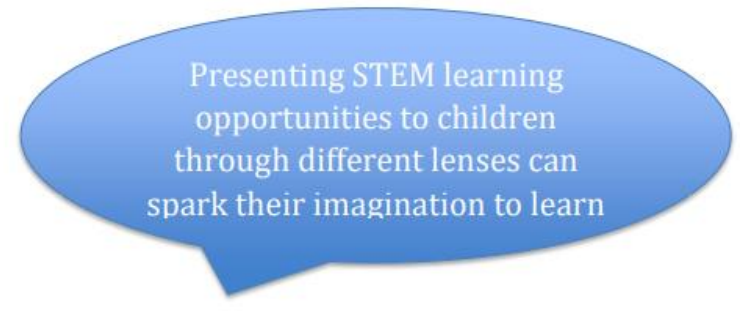

Fig 18: Quote 5

Theme 6: Digital Storytelling fosters computer science soft skills and STEM learning. Digital storytelling is a great idea for children to present what they learn in STEM. Digital storytelling is a powerful tool to help children synthesize and process what they have done; a quote by the teacher on this is depicted in Fig 19. The components of digital storytelling such as audio, video and presentation allows it to be a tool to cut across the diverse learning styles in elementary learners.

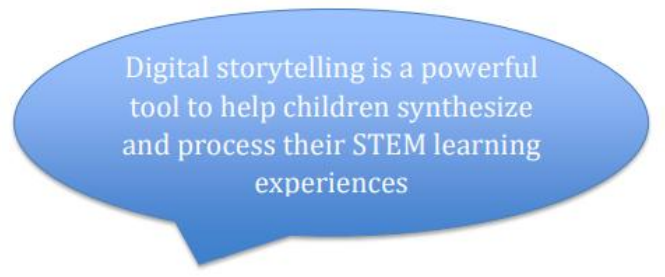

Fig 19: Quote 6

\subsection{Field Notes}

The view-points created by the elementary students in this study is that informal learning and digital storytelling plays an important role in their attitude and interest in learning STEM subjects and developing computer science soft skills. The majority of the elementary learners found digital storytelling to be engaging and motivating and expressed how it helps them learn and grasp STEM concepts easily. The findings reveal that informal learning such as after-school programs fosters critical thinking, deep understanding and persistence by offering time to work through hands-on activities without any pressure, allowing the elementary learners to learn about STEM related subjects at their own pace in a non-competitive environment. The digital stories created by the elementary learners included: animation, drawings, narration and music. Creating their digital stories of STEM learning concepts was a great way to explain and elaborate their ideas. Digital storytelling provided a compelling need for the elementary learners to read, listen, write and edit STEM information. Writing, adding images, creating videos, arranging a project story, and using imagination creatively were some of the skills developed using digital storytelling in the informal learning environment. These are typical soft computer science skills.

\section{CONCLUSION}

The call for increased participation in STEM learning has been a worldwide concern. The study therefore opines that exposing elementary learners to STEM learning, in a fun and relaxed atmosphere can instill a STEM interest into adulthood where career decisions are made. The approach considered in this study to expose children to STEM learning is the use of informal learning settings and digital storytelling. Digital storytelling was instrumental in matching elementary learner's 
to their learning style due to its audio, visual and text/write features. The cognitive theory of multimedia learning led to findings on how digital storytelling works in terms of media, sensory register, working memory and long-term memory which are typical computer science soft skills. This study showed that digital storytelling can be a powerful tool for developing computer science soft skills in elementary learners. Early Childhood Education lays the foundation for lifelong learning, so it is vital to incorporate approaches that would support and enhance learning. This research concludes that the STEM learning experiences gained from informal learning and digital storytelling prove to be highly influential in the choices they make in adulthood about further education and career pathways in computer science and other STEM fields. This study concludes that informal learning and digital storytelling are considered innovative pedagogical approaches that can engage elementary learners in deep and meaningful learning of computer science and other STEM concepts.

\section{REFERENCES}

[1] Robin, \& Bernard. 2008. A powerful technology tool for the 21 st century classroom. Theory Into Practice , 220228.

[2] David, E. 2007. The Power of Play: Learning What Comes Naturally. Da Capo Lifelong Books.

[3] Weckbacher, \& Okamoto. 2015. Discovering space in the elementary classroom. Journal of Education and Learning, 35-40.

[4] Robin, B., S. McNeil, and P. Yuksel. "Educational uses of digital storytelling around the world." Proceedings of SITE 2011 (2011).

[5] Sadik. 2008. Digital Storytelling: a meaningful technology integrated approach for engaged student learning. Educational Technology Research and Development , 487-506.

[6] Leonie, J. 2014. Learning Science Outside of School. In G. Norman, \& K. Sandra, Handbook of Research on Science Education. Routledge.

[7] Yuksel-Arslan, Yildirim, \& Robin. 2016. A phenomenological study:teachers' experiences of using digital storytelling in early childhood education. Educational Studies, 42(5), 427-445

[8] Robin, Bernard R. 2008."Digital storytelling: A powerful technology tool for the 21 st century classroom." Theory into practice $47.3: 220-228$.

[9] National Research Council. 2009 Learning science in informal environments: People, places, and pursuits. National Academies Press.

[10] Krathwohl, D. R., \& Anderson, L. W. 2010. Merlin C. Wittrock and the revision of Bloom's taxonomy. Educational psychologist, 45(1), 64-65.

[11] Dunn, \& Dunn. (1992). Teaching elementary students through their individual learning styles. Needhan Heights

[12] Marian, H., \& Jackson, C. 2016. Inquiry-based learning: a framework for assessing science in the early years. Early Child Development and Care, 1-12.

[13] Moore, D., \& Edwards, S. 2014. Play-based learning in early childhood education. Young Children's Play and Environmental Education in Early Childhood Education, Springer, 9-24.
[14] Roblyer, M. 2006. Integrating Educational Technology into Teaching. Upper Saddle River, NJ: Pearson Education Inc.

[15] Sylvester. 2013. A Child's Brain: Understanding How the Brain Works, Develops, and Changes During the Critical Stages of Childhood. First Skyhorse Publishing

[16] Tanenbaum, C. 2016. STEM 2026: A vision for innovation in STEM education. US Department of Education, Washington, DC.

[17] NAEYC.2013..http://www.naeyc.org/files/academy/file/ AllCriteriaDocument.

[18] NSF.2006. Informal Science Education(ISE) Program Solicitation.

[19] Martin. 2004. An emerging research framework for studying informal learning and schools. Science Education , 71-82.

[20] Riedinger. 2015. Identity Development of Youth during Participation at an Informal Science Education Camp. International Journal of Environmental \& Science Education , 453-475.

[21] Cicek. 2012. After school student club practices in U.S kindergarten thru 12th grade educational institutions. Journal of Educational and Instructional Studies in the World , 235-244.

[22] Ivala, Gachago, \& Condy. 2013. Enhancing student engagement with their studies: a digital storytelling approach. Scientific Research, 82-89.

[23] Dogan, B., \& Robin, B. 2008. Implementation of digital storytelling in the classroom by teachers trained in a digital storytelling workshop. In Society for Information Technology \& Teacher Education International Conference. pp. 902-907.

[24] Akpan-Obong, P. 2013. Letters to Nigeria: Journal of an African Woman in America.CreateSpace Independent Publishing Platform.

[25] Liu. 2011. Integrating Multimedia Education to improve Mathematical Learning. International Conference of Information Technology and Teacher Education (pp. 466-470). Chesapeake, VA: AACE.

[26] Sansosti, F. J., \& Powell-Smith, K. A. 2008. Using computer-presented social stories and video models to increase the social communication skills of children with high-functioning autism spectrum disorders. Journal of Positive Behavior Interventions, 10(3), 162-178.

[27] Royer, R., \& Richards, P. 2007. Increasing reading comprehension with digital storytelling. In EdMedia+ Innovate Learning (pp. 2301-2306).

[28] Donohue, C., \& Schomburg, R. (2017). Technology and interactive media in early childhood programs. Young Children

[29] 33. Bazeley, P. (2009). Mixed methods data analysis. Mixed methods research for nursing and the health sciences, 84-118.

[30] 35. Andrade, H., Huff, K., \& Brooke, G. (2012). Assessing learning. Education Digest, 78(3), 46-53. 